\title{
Experimental comparison of methods for simultaneous selection of two correlated traits in Tribolium. 2. Index selection and independent culling levels : a replicated single generation test
}

\author{
J.L. CAMPO and Carmen RODRIGUEZ
}

Departamento de Genética Cuantitativa y Mejora Animal,

Instituto Nacional de Investigaciones Agrarias, Carretera de La Coruña Km 7, 28040 Madrid, Spain

\begin{abstract}
Summary
Index selection (I) was compared with independent culling levels $(\mathrm{N})$ in ten replicates of a single generation selection experiment. Two correlated traits, egg laying between 7 and 11 days after adult emergence and adult weight at 12 days, were selected in Tribolium castaneum. Selection criteria included family means for egg laying and individual phenotypic values for adult weight. The response to index selection was greater than the response to independent culling levels for the aggregate genotype $(8.80,4.38)$ and the difference was highly significant $(P<.001)$. The predicted response to independent culling levels was slightly less than that for index selection for the aggregate genotype. The very large difference found in the index line relative to culling level line could be due to the fact that family selection was used for egg laying. Responses obtained for both individual traits were also greater in the selection index line, and the difference was significant $(P<.001)$ for egg laying $(8.13,3.96)$ but not for adult weight $(0.67,0.42)$. A greater response would be expected in the selection index line for each individual trait when optimum culling proportions are used in the culling levels line. Independent culling levels should be considered in practice as a relatively simple but inefficient selection method to improve egg laying and adult weight.
\end{abstract}

Key words : Index selection, independent culling levels, correlated traits, single generation test, Tribolium castaneum.

\section{Résumé}

Comparaison expérimentale de méthodes de sélection pour l'amélioration de deux caractères corrélés chez Tribolium. 2. Sélection sur index et sélection par niveaux indépendants : une expérience sur une génération, avec répétition

On a comparé la sélection sur index (I) et la sélection par niveaux indépendants $(\mathrm{N})$ dans une expérience de sélection sur une génération comportant 10 répétitions. On a réalisé la sélection chez Tribolium castaneum sur 2 caractères corrélés : la ponte d'œufs du $7^{\mathrm{e}}$ au $11^{\mathrm{e}}$ jour après l'émergence de l'adulte et le poids de l'adulte à l'âge de 12 jours. Les critères de sélection faisaient intervenir les moyennes de familles pour la ponte d'œufs et les valeurs phénotypiques individuelles pour le poids adulte. La réponse à la sélection sur index est plus grande que celle à 
la sélection par niveaux indépendants pour le génotype global $(8,80$ et 4,38 respectivement), la différence étant hautement significative $(\mathrm{P}<0,001)$. La réponse prédite à la sélection par niveaux indépendants est légèrement inférieure à la réponse prédite à la sélection sur index pour le génotype. L'importante différence observée entre les réponses à la sélection sur index et à la sélection par niveaux indépendants pourrait être due à l'utilisation d'une sélection familiale pour la ponte d'œufs. Les réponses obtenues sur chacun des 2 caractères sont, elles aussi, plus importantes avec la sélection sur index qu'avec la sélection par niveaux indépendants, la différence étant significative $(P<0,001)$ pour la ponte d'œufs $(8,13$ et 3,96 respectivement), mais non significative pour le poids adulte $(0,67$ et 0,42 respectivement). La réponse attendue pour chacun des caractères est plus grande dans la sélection sur index que dans la sélection par niveaux indépendants avec des intensités de sélection optimales. En pratique, la sélection par niveaux indépendants doit être considérée comme une méthode assez simple mais inefficace pour améliorer la ponte d'œufs et le poids adulte.

Mots clés : Sélection sur index, sélection par niveaux indépendants, caractères corrélés, expérience sur une génération, Tribolium castaneum.

\section{Introduction}

Multiple trait selection may be carried out by 3 main methods : index selection, independent culling levels and tandem selection. It has been theoretically shown (HAZel \& Lush, 1942 ; Young, 1961) that the index method is never less efficient than that of independent culling levels, though in some cases it may be no more efficient ; similarly, independent culling is never less efficient than tandem selection. A further method, selection of extremes (ABPLANALP, 1972), is theoretically more efficient than tandem selection, and falls below independent culling levels when the proportion selected is less than 0.50 .

The expected results about index, independent culling levels and tandem methods of selection, have been experimentally confirmed by SEN \& ROBERTSON (1964), selecting for bristle scores in Drosophila, and Doolitrle et al. (1972), selecting for litter size and weight gain in mice, even though they did not obtain significant differences among the methods. Experimental results by RASMUSON (1964), selecting for bristle scores in Drosophila, are in agreement with theoretical expectations for tandem selection, but the comparison between index and independent culling methods is contradictory in the 2 experiments that were made.

All the above comparisons consisted of multigeneration experiments. The use of replicated single generation experiments to obtain selection responses which could be considered as accurate estimates of theoretical responses, has been emphasised by BoHren (1975). These experiments have been applied to check the genetical theory concerning single trait selection (WILSON, 1974 ; GARwood et al., 1980 ; Garwood \& LowE, 1981) but not multiple trait selection theory.

Since those experimental results comparing the best 2 methods of multiple trait selection have not conclusively shown the theoretical advantage of the index over the independent culling method, in the present experiment selection was practised for egg laying and adult weight of Tribolium, comparing index selection and independent culling levels in ten replicates of a single generation of selection. The comparison between index and a modified tandem selection has been previously considered by Orozco et al. (1980) for these same traits, obtaining results in agreement with theoretical expectations. 


\section{Material and methods}

The population of Tribolium castaneum used in this study originated from the Consejo stock. During the experiment, lines were maintained in an incubator at a temperature of $33{ }^{\circ} \mathrm{C}$ and a relative humidity of $70 \mathrm{p}$. 100 . The culturing medium used consisted of 95 p. 100 wheat flour and 5 p. 100 brewer's yeast.

Ten replicates were used in this experiment. The unselected generation 0 of each line, in each of the 10 replicates, was produced by mating males and females randomly selected from the base population. The parents of the selected generation 1 were picked from generation 0 by the appropriate selection method and were mated in such a way that sib matings were avoided. The 2 lines in each replicate were differentiated by the method of selection : index (I) or independent culling levels (N). Each line was propagated by 25 single-pair matings per generation ; 5 male and 5 female offspring were individually weighed and the females scored for egg laying. With 25 males and 25 females selected each generation, the proportion selected was 0.20 in both lines.

The 2 traits selected, egg laying between 7 and 11 days after adult emergence and adult weight at 12 days, were given equal weights in the aggregate genotype. The unit of measurement for adult weight was the tenth of a milligram.

The index coefficients have been calculated from previous parameters estimates (CAmpo \& Rodriguez, 1985). The selection index in the I line was, in females :

$$
\mathrm{I}=0.69 \overline{\mathrm{x}}_{1}+1.34 \mathrm{x}_{2}
$$

ınd, in males :

$$
\mathrm{I}=0.57 \overline{\mathrm{x}}_{1}+1.53 \mathrm{x}_{2}
$$

where $\bar{x}_{1}$ and $x_{2}$ stand for the mean of full-sib families for egg laying and the individual phenotypic value for adult weight, respectively. In the $\mathrm{N}$ line, the males and females were separately ranked for $\vec{x}_{1}$ and $x_{2}$, then selection was simultaneously practised in the 2 rankings till the proportion selected was achieved (BELL \& BURRIS, 1973).

Comparison between responses to selection obtained in each line was made by analysis of variance, mixed model, lines being considered as a fixed factor and replicates as a random factor. Estimates of heritabilities and genetic and phenotypic correlations for both traits in the base population were obtained by analysis of variancecovariance of full-sib families.

The expected response to selection for each trait separately $\left(\Delta \mathrm{G}_{1}, \Delta \mathrm{G}_{2}\right)$ and for the aggregate genotype $(\Delta \mathrm{H})$ have been previously given by CAMPO \& RodRIGUEz (1985) in the $\mathrm{I}$ line. The expected responses in $\mathrm{N}$ line are, in females :

$$
\begin{array}{ll}
\Delta G_{1}=\left[a_{1} h_{1}^{2} \frac{\alpha^{G}}{\sqrt{n \alpha^{\mathrm{P}}}}+a_{2} h_{1} h_{2} r_{12}^{G}\right] \cdot \sigma_{1} & ; \Delta H=\Delta G_{1}+\Delta G_{2} \\
\Delta G_{2}=\left[a_{1} h_{1} h_{2} r_{12}^{G} \frac{\alpha^{G}}{\sqrt{n \alpha^{\mathrm{P}}}}+a_{2} h_{2}^{2}\right] \cdot \sigma_{2} &
\end{array}
$$


and, in males :

$$
\begin{array}{ll}
\Delta G_{1}=\left[a_{1} h_{1}^{2} \frac{1}{2} \sqrt{\frac{n}{\alpha^{\mathrm{P}}}}+a_{2} h_{1} h_{2} r_{12}^{G}\right] \cdot \sigma_{1} & ; \Delta H=\Delta G_{1}+\Delta G_{2} \\
\Delta G_{2}=\left[a_{1} h_{1} h_{2} r_{12}^{G} \frac{1}{2} \sqrt{\frac{n}{\alpha^{\mathrm{P}}}}+a_{2} h_{2}^{2}\right] \cdot \sigma_{2} &
\end{array}
$$

where $h^{2}, \sigma^{2}$ and $r_{12}^{G}$ stand for the heritabilities, phenotypic variances and genetic correlation coefficient respectively, $\mathrm{n}$ is the family size for egg laying, and :

$$
\begin{aligned}
& a_{1}=\frac{i_{1}-r_{\hat{x}_{1} x_{2}} \cdot i_{2}}{1-r_{\bar{x}_{1} x_{2}}^{2}} ; a_{2}=\frac{i_{2}-r_{\tilde{x}_{1} x_{2}} \cdot i_{1}}{1-r_{\bar{x}_{1} x_{2}}^{2}} \\
& \alpha^{\mathbf{G}}=1+(n-1) \frac{1}{2} ; \alpha^{P}=1+(n-1) \frac{1}{2} h_{1}^{2}
\end{aligned}
$$

The phenotypic correlation between the family mean for egg laying and the individual adult weight is, in females :

$$
r_{\bar{x}_{1} x_{2}}=\frac{r_{12}+\frac{1}{2}(n-1) r_{12}^{G} h_{1} h_{2}}{\sqrt{n \alpha^{p}}}
$$

and, in males :

$$
\mathbf{r}_{\tilde{x}_{1} \mathbf{x}_{2}}=\frac{1}{2} \mathbf{r}_{12}^{\mathrm{G}} \mathbf{h}_{1} \mathbf{h}_{2} \sqrt{\frac{\mathbf{n}}{\alpha^{\mathrm{P}}}}
$$

where $r_{12}$ stands for the phenotypic correlation coefficient. The selection intensities for each trait $\left(i_{1}, i_{2}\right)$ have been given by Young \& WeILER (1960).

\section{Results}

The parameters of the base population are shown in table 1. Estimates agree very well with those previously reported by us (CAMPo \& Rodriguez, 1985) in the Consejo population. Egg laying showed a much greater variation than adult weight, both traits having intermediate values of heritability, a little higher for adult weight. There were positive phenotypic and genetic correlations, the phenotypic coefficient being smaller than the genetic one. Females were heavier than males; however, phenotypic and genetic variances in males and females were homogeneous and therefore both sexes were analyzed together in this study. 
TABLE 1

Parameters of the base population.

\begin{tabular}{|c|c|c|}
\hline \multirow{2}{*}{ Parameter } & \multicolumn{2}{|c|}{ Trait } \\
\hline & Egg laying & Adult weight ${ }^{(a)}$ \\
\hline Mean & $32.21 \pm 0.39$ & $21.72 \pm 0.05$ \\
\hline Phenotypic variance & 193.94 & 7.26 \\
\hline Coefficient of variation $(\%)$ & 43.24 & 12.41 \\
\hline Sample size & 1252 & 2596 \\
\hline Heritability & $0.33 \pm 0.03^{(b)}$ & $0.46 \pm 0.03$ \\
\hline \multicolumn{3}{|l|}{ Correlation : } \\
\hline Phenotypic $\ldots \ldots \ldots \ldots \ldots \ldots \ldots$ & \multicolumn{2}{|c|}{$0.31 \pm 0.09$} \\
\hline$\ldots \ldots \ldots \ldots \ldots$ & \multicolumn{2}{|c|}{$0.75 \pm 0.02$} \\
\hline
\end{tabular}

(a) Sexes pooled.

(b) Heritability of family means was 0.60 .

The observed responses to selection for the aggregate genotype are indicated in table 2 , for the 10 single generation tests. In no replicate did the index line fail to produce positive response for the aggregate genotype, while the independent culling line produced negative response in 2 replicates and produced practically no change in another replicate. Mean progress from each method of selection indicates that the index line exceeded the independent culling line, being about twice as good. In all replicates selection response was greater in the I line than in the $\mathbf{N}$ line. The analysis of variance of the selection progress realized is shown in table 3 . Selection methods and replicates were highly significant sources of variation $(P<.001)$ when tested by the interaction variance. The validity of the significance between replicates assumed the absence of significant line $\mathrm{x}$ replicate interaction.

TABLE 2

Observed responses to selection for $\mathrm{H}$ units ${ }^{(\mathrm{a})}$ and each individual trait in the index $(I)$ and independent culling $(N)$ lines.

\begin{tabular}{c|r|r|r|r|r|r}
\hline \hline \multirow{2}{*}{ Replicate } & \multicolumn{2}{|c|}{$H$ units } & \multicolumn{2}{c|}{ Egg-laying } & \multicolumn{2}{c}{ Adult weight } \\
\cline { 2 - 7 } & \multicolumn{1}{|c|}{ I line } & N line & I line & N line & I line & N line \\
\hline & 18.42 & 13.04 & 18.34 & 12.46 & 0.08 & 0.58 \\
2 & 9.12 & 7.85 & 8.15 & 7.99 & 0.97 & -0.14 \\
3 & 8.63 & 5.46 & 7.61 & 4.19 & 1.02 & 1.27 \\
4 & 12.09 & 4.90 & 11.30 & 3.92 & 0.79 & 0.98 \\
5 & 0.91 & -3.49 & 0.34 & -3.35 & 0.57 & -0.14 \\
6 & 3.86 & 0.06 & 3.58 & -0.16 & 0.28 & 0.22 \\
7 & 8.08 & 4.54 & 7.65 & 4.38 & 0.43 & 0.16 \\
8 & 12.02 & 8.12 & 11.10 & 7.11 & 0.92 & 1.01 \\
9 & 10.57 & 4.24 & 9.49 & 4.32 & 1.08 & -0.08 \\
10 & 4.33 & -0.88 & 3.76 & -1.24 & 0.57 & 0.36 \\
\hline Mean & 8.80 & 4.38 & 8.13 & 3.96 & 0.67 & 0.42 \\
\hline
\end{tabular}

(a) Egg laying plus adult weight. 
The observed responses to selection for each individual trait are also indicated in table 2. For egg laying, the index line had positive selection response in all replicates ; the independent culling line showed positive response only in 7 replicates, having negative response in 3 other replicates. The response was always larger in the index line than in the independent culling line. The difference between average gains in egg laying was significant (tabl. 3). The mean value for adult weight increased in all replicates of the index line, increasing in 7 replicates of the independent culling line and having negative response in the other 3 replicates. Even though the index line showed a trend to be superior to the independent culling line, the difference among mean gains was not significant. The above results show that the response to selection in the aggregate genotype was mainly due to an increase in egg laying. The higher homogeneity observed in the unselected generation 0 means for adult weight than for egg laying was consistent with the variation found in the base population for each trait. The coefficients of variation of these mean values were about 3 p. 100 and 12 p. 100 for adult weight and egg laying, respectively.

TABLE 3

Analysis of variance of responses to selection for the aggregate genotype and for both individual traits.

\begin{tabular}{|c|c|c|c|c|c|c|c|}
\hline \multirow{2}{*}{ Source of variation } & \multirow{2}{*}{ df } & \multicolumn{2}{|c|}{$H$ units } & \multicolumn{2}{|c|}{ Egg laying } & \multicolumn{2}{|c|}{ Adult weight } \\
\hline & & MS & $\mathbf{F}$ & MS & F & MS & F \\
\hline Lines & 1 & 101.30 & $61.4^{* * *}$ & 86.95 & $47.8^{* * *}$ & 0.31 & 1.94 \\
\hline Replicates & 9 & 45.32 & $27.5^{* * *}$ & 45.09 & $24.8^{* * *}$ & 0.22 & 1.37 \\
\hline $\mathbf{L} \times \mathbf{R}$ & 9 & 1.65 & & 1.82 & & 0.16 & \\
\hline
\end{tabular}

*** $\mathrm{P}<.001$.

The selection intensities for egg laying and adult weight in both lines are shown in table 4 . In the independent culling line the intensity of selection was larger for adult weight than for egg laying. The observed selection intensities do not agree with those predicted (Young \& WeILer, 1960). The expected values for egg laying and adult weight range approximately from $(0.40,1.40)$, when the selection pressure is different in egg laying and in adult weight, to $(1.00,1.00)$ when it is identical in both traits. If an intensity of selection approximately equal to 0.80 is given for adult weight, a value greater than 1.00 is predicted for egg laying. In the line selected by independent culling levels the selection differentials for egg laying exceeded those for adult weight, as was expected because of the greater value for the phenotypic variance of the family means for egg laying than for the phenotypic variance of the adult weight. Realized heritabilities were 0.48 for egg laying and 0.23 for adult weight ; in both cases the realized values are smaller than those calculated in the base population ( 0.60 and 0.46 respectively).

The average value throughout the 10 replicates of the intensities of selection obtained in the index line (tabl. 4) was slightly smaller than the theoretical value (1.39). Selection differentials observed in each replicate of the line selected by the index method were similar to those previously obtained by us (CAMPo \& RodriguEz, 1985 ) in the theoretical index line. Realized heritability was 0.67 and it agrees very well 
TABLE 4

Intensities of selection (i) observed in the index line and secondary intensities for egg laying (i, and adult weight $\left(i_{2}\right)$ in both lines.

\begin{tabular}{|c|c|c|c|c|c|c|c|c|c|c|c|c|}
\hline \multirow{2}{*}{\multicolumn{2}{|c|}{ Line }} & \multicolumn{10}{|c|}{ Replicates } & \multirow{2}{*}{ Mean } \\
\hline & & 1 & 2 & 3 & 4 & 5 & 6 & 7 & 8 & 9 & 10 & \\
\hline \multirow{2}{*}{$\mathbf{N}$} & $i_{1}$ & 0.60 & 0.49 & 0.28 & 0.37 & 0.43 & 0.46 & 0.76 & 0.66 & 0.64 & 0.69 & 0.54 \\
\hline & $\mathrm{i}_{2}$ & 1.12 & 0.66 & 0.95 & 0.84 & 0.94 & 0.48 & 0.92 & 1.06 & 0.68 & 0.47 & 0.81 \\
\hline \multirow{3}{*}{ I } & i & 1.29 & 1.21 & 1.10 & 1.29 & 1.29 & 1.32 & 1.16 & 1.17 & 1.03 & 1.28 & 1.21 \\
\hline & $i_{1}$ & 0.31 & 0.40 & 0.62 & 0.62 & 0.50 & 0.56 & 0.51 & 0.44 & 0.30 & 0.33 & 0.46 \\
\hline & $\mathrm{i}_{2}$ & 1.26 & 1.09 & 1.09 & 1.14 & 1.19 & 1.31 & 1.05 & 1.07 & 1.02 & 1.41 & 1.16 \\
\hline
\end{tabular}

with the heritability of the selection index calculated in the base population which was 0.75. As in the independent culling line, the intensity of selection was larger for adult weight than for egg laying (tabl. 4). The secondary selection intensities for egg laying from the index line were in general smaller than the corresponding values obtained in the independent culling line, while selection intensities for adult weight were greater in the index line.

\section{Discussion}

Concerning the aggregate genotype the selection index line had a significantly better response than the independent culling line, showing that the index was a superior method to improve egg laying and adult weight simultaneously. The index also gave a greater response for both individual traits, the lines differing significantly for egg laying only.

Expected responses to selection per generation have been calculated from previous parameter estimates (CAMPo \& RoDriguez, 1985), not those given in table 1, since the index coefficients were calculated with these previous estimates. Expectations of gains using the parameters of the base population (tabl. 1) were very similar. In theory, a greater response should be expected with index selection than with independent culling selection for the aggregate genotype ( $\mathrm{H}$ units). The greatest response with independent culling selection is expected when the intensity of selection is approximately 1.2 for egg laying and 0.8 for adult weight ; it turns out to be 8.65 (when the intensity of selection is equal for both traits the expected response is 8.56). Since the theoretical expected response is 8.95 for index selection the relative efficiency of independent culling should be approximately 0.96 .

Independent culling levels performed surprisingly badly. The very large difference actually found could be due to the fact that family selection was used for egg laying under selection with independent culling levels; it could have resulted in unequal selection intensities for the 2 traits and thus put culling level selection at a possible disadvantage in selection efficiency. Moreover, the total response to selection in the aggregate genotype was mainly due to egg laying. On the other hand, the selection scheme used under independent culling levels (BELL \& BURRIS, 1973) deviates slightly 
from that originally developed by HAZEL \& LUSH (1942) and could affect the assumptions and the solutions provided by Young \& WeILER (1960) for computing the expected genetic changes. Selection intensities were not first optimized theoretically, even though the observed value for adult weight was near the optimum combination of culling while the observed value for egg laying was very far. The superiority of the index method with respect to independent culling levels was shown in all 10 replicates ; that consistency in the relative superiority for the selection index gives a great accuracy to the conclusions of the experiment.

The expected response for each individual trait, when the intensity of selection is approximately 1.2 for egg laying and 0.8 for adult weight, should be also smaller in the independent culling line. It turns out to be 7.29 for egg laying compared with the expected one in the selection index line (7.47) and 1.35 for adult weight compared with 1.50. The relative efficiency expected in the $\mathrm{N}$ line is 0.98 for egg laying and 0.90 for adult weight.

The superiority of the index method compared with the independent culling levels one which was found in this study agrees with the general results reported by HAzEL \& LusH (1942) and with the theoretical results obtained by Young (1961) concerning the simultaneous improvement of correlated traits selected with the same economic weights. Since efficiency of culling level selection relative to index selection increases with increasing total selection intensity, with $20 \mathrm{p}$. 100 total selection it could be expected culling level selection to be relatively disadvantageous. On the other hand, the superiority of the index is maximum when the traits are of equal importance and it is higher when the phenotypic correlation is low.

The proportion of realized versus predicted response for the aggregate genotype was not very high in the independent culling line ( 0.50 approximately) as a consequence of the lack of positive response in 3 replicates. If these replicates were not included in the analysis, the observed response to selection would be 6.88 , very close to the expected response calculated before. The negative selection responses of some replicates in the culling level line could lead to the conclusion that single generation selection experiments do not fully explore the potential spectrum of factors entering real situations where selection is long-term and with highly heritable traits results in substantial responses. However, the proportion of realized versus predicted response for the aggregate genotype was very high in the index line $(0.98)$; this proportion is clearly different from that obtained by us in a multigeneration experiment (CAMPO \& RoDRIGUEZ, 1985). These results could confirm the value of highly replicated single generation experiments for testing genetic theory, as was emphasized by BoHren (1975). In experiments of this type, the problem of differential inbreeding levels can be eliminated and the net effect of differential population sizes should be of no consequence. Other experiments involving single generation selection have been applied to test the efficiency of selection methods to improve a single trait. In agreement with the present study GARwoon et al. (1980) found significant differences between individual and family selection in chickens. In contrast to us WILSON (1974), comparing individual, family and combination selection in Tribolium, and GARwOOD \& Lowe (1981), comparing family and combination selection in chickens, did not detect significant differences between methods of selection.

The principal consequences which can be extracted from the present study are that given the special conditions of this experiment (intermediate values of heritability, positive phenotypic and genetic correlations, equal economic weights, total selection 
intensity not very high and family selection for one trait), the selection index method is clearly better than independent culling levels. The small efficiency showed by the independent culling levels suggests that this method should not be, in these conditions, applied in practical breeding programs, even though the advantages of minimal record maintenance and animal handling increase its attraction. On the other hand, the arbitrary culling levels sometimes applied can be very far from the optimum values.

Received May 17, 1985.

Accepted April 9, 1986.

\section{Acknowledgements}

We are grateful to Dr. F. Orozco and Dr. C. Lopez-Fanjul for their advices and help in many aspects of the work.

\section{References}

Abplanalp H., 1972. Selection of extremes. Anim. Prod., 14, 11-15.

Bell A.E., Burris M.J., 1973. Simultaneous selection for two correlated traits in Tribolium. Genet. Res., 21, 29-46.

BoHren B.B., 1975. Designing artificial selection experiments for specific objectives. Genetics, 80 , 205-220.

CAmpo J.L., Rodriguez M.C., 1985. Experimental comparison of methods for simultaneous selection of two correlated traits in Tribolium. I. Empirical and theoretical selection indexes. Theor. Appl. Genet., 71, 93-100.

Doolittle D.P., Wilson S.P., Hulbert L.L., 1972. A comparison of multiple trait selection methods in the mouse. J. Hered., 63, 366-372.

Garwood V.A., Lowe P.C., Bohren B.B., 1980. An experimental test of the efficiency of family selection in chickens. Theor. Appl. Genet., 56, 5-9.

GARWOOD V.A., LowE P.C., 1981. A comparison of combination and family selection in chickens. Poultry Sci., 60, 285-288.

HAZEL L.N., LuSH J.L., 1942. The efficiency of three methods of selection. J. Hered., 33, 393399.

Orozco F., Campo J.L., Fuentes M.C., Lopez-Fanjul C., Tagarro P., 1980. A comparison between crossbreeding and index selection for the simultaneous improvement of two traits in Tribolium castaneum. In : ROBERTSON A. (ed.), Selection Experiments in Laboratory and Domestic Animals, 37-52. Commonwealth Agricultural Bureaux, U.K.

Rasmuson M., 1964. Combined selection for two bristle characters in Drosophila. Hereditas, 51, 231-256.

Sen B.K., Robertson A., 1964. An experimental examination of methods for the simultaneous selection of two characters using Drosophila melanogaster. Genetics, 50, 199-209.

WiLson S.P., 1974. An experimental comparison of individual, family and combination selection. Genetics, 76, 823-836.

Young S.S.Y., 1961. A further examination of the relative efficiency of three methods of selection for genetic gains under less restricted conditions. Genet. Res., 2, 106-121.

Young S.S.Y., WeILER H., 1960. Selection for two correlated traits by independent culling levels. J. Genetics, 57, 329-338. 